\title{
Erratum to: Micronized/ultramicronized palmitoylethanolamide displays superior oral efficacy compared to nonmicronized palmitoylethanolamide in a rat model of inflammatory pain
}

\author{
Daniela Impellizzeri ${ }^{1 \dagger}$, Giuseppe Bruschetta ${ }^{1 \dagger}$, Marika Cordaro ${ }^{1}$, Rosalia Crupi ${ }^{1}$, Rosalba Siracusa ${ }^{1}$, \\ Emanuela Esposito ${ }^{1}$ and Salvatore Cuzzocrea ${ }^{1,2^{*}}$
}

\section{Erratum}

The authors would like to issue an erratum for this article [1], and would like to declare the following competing interests which we inadvertently failed to include in our original publication. The authors would like to apologise for this omission.

\section{Competing interests}

Dr. Salvatore Cuzzocrea, researcher on the study team, is co-inventor on patent WO2013121449 A8 (Epitech Group SpA) which deals with compositions and methods for the modulation of amidases capable of hydrolysing $\mathrm{N}$-acylethanolamines useable in the therapy of inflammatory diseases. Moreover, Dr. Cuzzocrea is also a co-inventor with Epitech group on the following patents:

1. EP 2821083

2. MI2014 A001495

3. 102015000067344

No other authors have competing interests.

Ethics approval and consent to participate

The study [1] was approved by the University of Messina Animal Care Review Board: protocol number 8/U-apr 16.

Received: 24 May 2016 Accepted: 24 May 2016

Published online: 31 May 2016

\footnotetext{
*Correspondence: salvator@unime.it

${ }^{\dagger}$ Equal contributors

'Department of Biological and Environmental Sciences, University of Messina, Viale Ferdinando Stagno D'Alcontres, no 31, Messina 98166, Italy

${ }^{2}$ Manchester Biomedical Research Centre, Manchester Royal Infirmary,

University of Manchester, Manchester, Oxford Rd, Manchester M13 9WL, UK
}

Reference

1. Impellizzeri D, Bruschetta G, Cordaro M, Crupi R, Siracusa R, Esposito E, Cuzzocrea S. Micronized/ultramicronized palmitoylethanolamide displays superior oral efficacy compared to nonmicronized palmitoylethanolamide in a rat model of inflammatory pain. J Neuroinflammation. 2014;11:136. doi:10.1186/s12974-014-0136-0.
Submit your next manuscript to BioMed Central and we will help you at every step:

- We accept pre-submission inquiries

- Our selector tool helps you to find the most relevant journal

- We provide round the clock customer support

- Convenient online submission

- Thorough peer review

- Inclusion in PubMed and all major indexing services

- Maximum visibility for your research

Submit your manuscript at www.biomedcentral.com/submit 